\title{
Calibrating Sentinel-2 Imagery with Multispectral UAV Derived Information to Quantify Damages in Mediterranean Rice Crops Caused by Western Swamphen (Porphyrio porphyrio)
}

\author{
Magda Pla ${ }^{1, *(\mathbb{D}, \text { Gerard Bota }}{ }^{1}\left(\mathbb{D}\right.$, Andrea Duane ${ }^{1}$, Jaume Balagué ${ }^{1}$, Antoni Curcó ${ }^{4}$, \\ Ricard Gutiérrez ${ }^{5}$ and Lluís Brotons ${ }^{1,2,3}$ (D) \\ 1 InForest JRU (CTFC-CREAF), Carretera de Sant Llorenç de Morunys Km 2, 25280 Solsona, Lleida, Spain; \\ gerard.bota@ctfc.cat (G.B.); andrea.duane@ctfc.cat (A.D.); jaume.balague@ctfc.es (J.B.); \\ lluis.brotons@ctfc.cat (L.B.) \\ 2 Centre for Ecological Research and Forestry Applications (CREAF), 08193 Cerdanyola del Vallès, Spain \\ 3 Spanish National Research Council (CSIC), 08193 Cerdanyola del Vallès, Spain \\ 4 Ebro Delta Natural Park, Government of Catalonia, Av. Catalunya, 46, 43580 Deltebre, Spain; \\ acurcom@gencat.cat \\ 5 Ministry of Territory and Sustainability, Government of Catalonia, Dr. Roux, 80, 08017 Barcelona, Spain; \\ rgutierrez@gencat.cat \\ * Correspondence: magda.pla@ctfc.cat; Tel.: +34-973-481-752
}

Received: 22 March 2019; Accepted: 13 May 2019; Published: 21 May 2019

\begin{abstract}
Making agricultural production compatible with the conservation of biological diversity is a priority in areas in which human-wildlife conflicts arise. The threatened Western Swamphen (Porphyrio porphyrio) feeds on rice, inducing crop damage and leading to decreases in rice production. Due to the Swamphen protection status, economic compensation policies have been put in place to compensate farmers for these damages, thus requiring an accurate, quantitative, and cost-effective evaluation of rice crop losses over large territories. We used information captured from a UAV (Unmanned Aerial Vehicle) equipped with a multispectral Parrot SEQUOIA camera as ground-truth information to calibrate Sentinel-2 imagery to quantify damages in the region of Ebro Delta, western Mediterranean. UAV vegetation index NDVI (Normalized Difference Vegetation Index) allowed estimation of damages in rice crops at $10 \mathrm{~cm}$ pixel resolution by discriminating no-green vegetation pixels. Once co-registered with Sentinel grid, we predicted the UAV damage proportion at a $10 \mathrm{~m}$ resolution as a function of Sentinel-2 NDVI, and then we extrapolated the fitted model to the whole Sentinel-2 Ebro Delta image. Finally, the damage predicted with Sentinel-2 data was quantified at the agricultural plot level and validated with field information compiled on the ground by Rangers Service. We found that Sentinel2-NDVI data explained up to $57 \%$ of damage reported with UAV. The final validation with Rangers Service data pointed out some limitations in our procedure that leads the way to improving future development. Sentinel2 imagery calibrated with UAV information proved to be a viable and cost-efficient alternative to quantify damages in rice crops at large scales.
\end{abstract}

Keywords: Sentinel; UAV; Parrot SEQUOIA; multispectral; vegetation indices; rice crops; western swamphen

\section{Introduction}

Addressing human-wildlife conflicts is a fundamental challenge for conservation practitioners. In some areas of the planet, the loss of lives, crops, or live-stock because of wildlife has significant 
consequences for people's livelihoods and their food and agricultural security [1,2]. Reconciling the conservation of endangered species with human activities, as well as with socioeconomic uses and human security, has been the subject of numerous studies and management programs. The most commonly implemented actions are aimed at mitigating wildlife negative effects on agricultural production and human health through mitigation operations or economical compensations for losses caused by wildlife [3-5]. Quantifying and mapping wildlife-caused damages is essential to carry out both kind of actions. Most methodologies are aimed at developing predictive risk maps [6], but in the context of human-wildlife conflicts, it is crucial to develop accurate protocols for the reliable verification of the authority of the causative species and their relation with damage claims [7]. These protocols are fundamental in creating public trust in the legitimacy of compensation programs, and in avoiding fraud and moral hazards. Finding simple and inexpensive methods to quantify damages is a major challenge in decreasing the cost-benefit ratio to achieve conservation objectives. Medium resolution remote sensing imagery as low-cost Unmanned Aerial Vehicles (UAV) has arisen as an essential tool to meet this challenge.

Rice crops (Oriza sativa) are one of the agricultural habitats most affected by human-wildlife conflicts $[8,9]$. Large populations of aquatic birds inhabit these agricultural habitats due to their high productivity levels and similarity to natural wetlands [3]. Rice crops are one of the most important bases of the rural economy in many regions of the world. For instance, in the region of the Ebro Delta in the western Mediterranean, with more than 20,000 ha of surface area, the rice fields represent an essential economic revenue, accounting for a significant proportion of the Spanish rice production. At the same time, the Ebro Delta constitutes a fundamental area for the conservation of biodiversity. Hence, some protection figures have been established to protect the area, namely the Natural Park and Wildlife Reserve, Wetlands of International Importance (Ramsar Convention), Natura 2000 Network Space, and recently, Biosphere Reserve for UNESCO's Man and the Biosphere Program. In this context, striving for agricultural production compatible with the conservation of the biological wealth of the Delta is a priority objective of public administrations and represents an important challenge for landscape managers.

The Western Swamphen is a species of conservation interest in Europe that is included in Annex I of the Birds Directive and is considered a Least Concern species at the European level [10]. The population in Europe is estimated at 3400-3800 pairs [10]. At the moment, the Iberian Peninsula contains $81 \%$ of this population [10], and thanks to the application of conservation measures, at the end of twentieth century the species had naturally recolonized some of the Iberian wetlands where it had disappeared [11]. However, its population increase in the Ebro Delta has caused the emergence of conflicts with rice farmers, since the Western Swamphen uses rice crops as feeding grounds, leading to crop losses. Since the Western Swamphen is protected by national and European legislation, actions taken to reduce crop damages that may lead to changes in its conservation status, such as lethal control or captures and translocations, cannot be undertaken without an assessment of alternative measures. In this context, objectively quantifying Swamphen damage as accurately as possible is a requisite. Initially, the damage assessment was only carried out based on field visits by regional ranges to the affected crops. The obvious damages near the roads were easily evaluable and quantifiable, but the less obvious damages located further away from the roads remained difficult to evaluate. In addition, this method may be subjected to certain levels of subjectivity and without accurate evaluation of the committed error. Thus, defining an objective methodology to quantify the damages is an essential challenge, both for the benefit of the species and from an economic point of view.

Remote sensing medium resolution imagery has shown a great capacity to quantify damages in crop lands. The satellites MODIS and Landsat have been widely used [12-14], but Sentinel-2, especially for its finer resolution, constitutes a major asset for this kind of application $[15,16]$. However, due to the types of damages that affect the majority of the crops, satellite resolutions are still too coarse. In this sense, imagery provided by the high spatial resolution commercial satellites as Deimos-2, GeoEye-2, QuickBird, or WorldView-2 could be an appropriate option $[14,17,18]$. Nevertheless, in some specific 
decision making contexts the cost-benefit ratio is too high, especially if multiple images of different dates are required or large surfaces are needed. The use of lightweight UAV usually implies lower economic costs than other remote sensing techniques when surveying relatively small areas (tens of hectares) and can be a very good alternative [19-24], especially due to its finer resolution (better than $20 \mathrm{~cm}$ ) and versatility. Lightweight UAVs and photogrammetric derived information as Digital Surface Models (DSM) have been used to calculate crop damages by means of crop height estimation [25] or grapevine canopy changes [26]. UAV multispectral information is also becoming very important due to its ability to asses vegetation stress and damages through vegetation indices [27,28]. In fact, this ability can be very useful to detect Western Swamphen damages, usually resulting in small and medium vegetation gaps and plant vigor decreases in rice crops. However, mapping large areas with UAV, such as the Ebro Delta, with more than 20,000 ha, may require considerable economic and technical efforts [29]. In this context, some works use UAV information as field data to calibrate imagery from coarser resolution satellites, such as Landsat or Sentinel-2, with correlative methodologies [30,31].

In addition to the developments in quantitative methodological work-flows, it is equally important to offer the results in a comprehensible and useful format for managers responsible for damage assessment and economic compensation guidance [6]. Developing comprehensible products to boost conservation strategies at high efficiency ratios is a prerequisite.

Thus, this work has two main objectives: the first one is to test the ability to use UAV multispectral imagery as ground truth information for calibrating the physical parameters calculated on medium resolution satellite remote sensing imagery from Sentinel-2; the second is to translate the calibrated remote sensing quantification into understandable and useful products for the landscape managers. We tested these questions in the Ebro Delta region, in NE Spain, with rice crops affected by Western Swamphen activity.

\section{Study Area and Species}

The Ebro Delta constitutes one of the largest wetland areas of the western Mediterranean, at $320 \mathrm{~km}^{2}$. Its location per Ramsar site designation is $40^{\circ} 43^{\prime} \mathrm{N}, 00^{\circ} 44^{\prime} \mathrm{E}$ (Figure 1). The delta protrudes around $30 \mathrm{~km}$ seaward, with a triangular shape created by the river. Of this, $20 \%$ of the area corresponds to natural habitats, $75 \%$ is arable land, and the rest are urban areas. Most of the arable land is used for intensive rice agriculture, but noticeable is that this type of agriculture was not implemented until the late nineteenth century. Natural habitats encompass rich ecosystems corresponding to rivers, sea, bays, beaches, dunes, riparian forests, coastal lagoons, and saltmarshes. As a result, the Ebro Delta was declared a natural park in 1983 and a biosphere reserve in 2013. Rice paddies occupy 65\% of the Ebro Delta area, and together with tourism, constitute the main economic resource for the approximately 15,000 local residents [3]. An abundant population of Western Swamphen has been recorded, mainly distributed in natural wetlands and their surroundings, including rice fields [32]. At present, the Iberian Peninsula constitutes most of its European population and at the end of the 20th century there was a significant population growth thanks to the implementation of active conservation measures [11]. Western Swamphen cause rice damage through the cutting of stems for feeding and by trampling during displacement (creating corridors) within the rice field (Figure 2). Also, in the case of individual breeding, plaques are generated in the crop (Figure 2, right) due to the construction of nests and the consequent trampling around them. The effects of Western Swamphen in the field are therefore: (1) absence of plants (stems cut) and (2) damaged plants that rebound (with smaller size and lower rice productivity). Overall, the affected field experiences decreased rice productivity. Due to existing regulation [33], the government of Catalonia (regional administration) compensates the affected farmers according to the surface area damaged. In the Ebro Delta, administrators had paid up to $€ 203,450$ per year from 2003 to 2016 to compensate for damages on about 21,000 ha of rice fields [3]. 


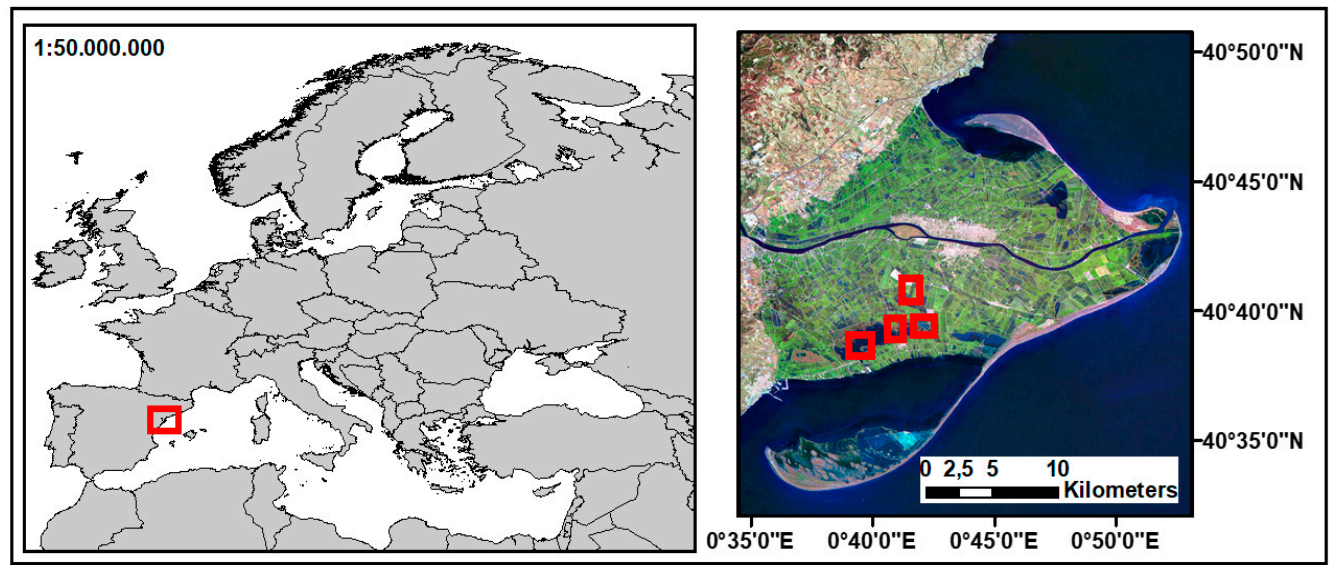

Figure 1. (Left) Ebro Delta location (red rectangle) over a Europe Administrative limits map. (Right) Landsat image of the Ebro Delta. Green land cover corresponds to rice crops. Red rectangles show the four agricultural plots where UAV (Unmanned Aerial Vehicle) images were captured (surveyed plots).
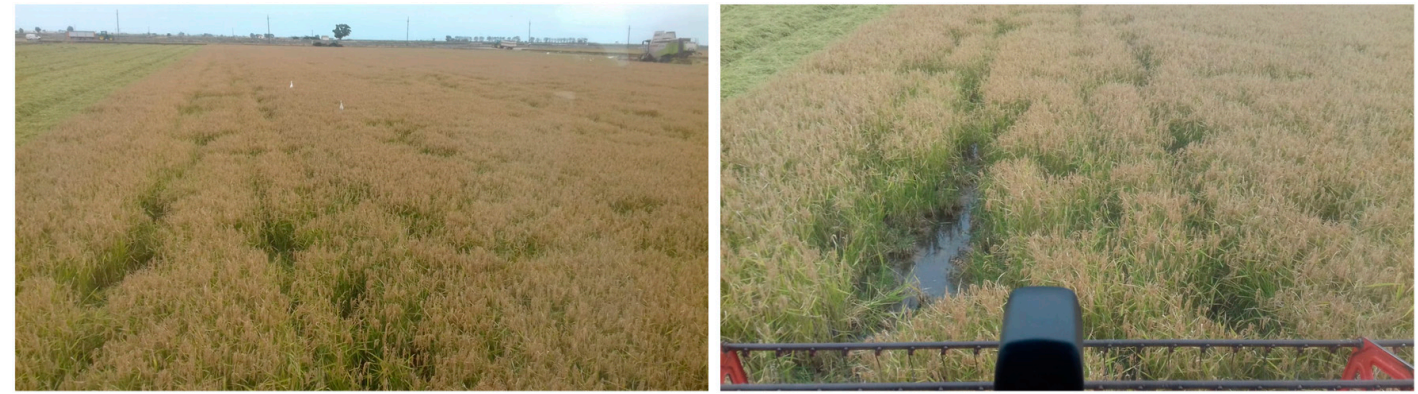

Figure 2. Field photos of damage caused by the western Swamphen on rice plots. (Left) Corridors with damaged plants within the rice field, the most abundant damages. (Right) A plaque with a lack of vegetation leaving the crop water visible.

\section{Material and Methods}

We aimed to: (1) calibrate Sentinel-2 images with UAV-derived data, and then (2) validate the generated Sentinel-2 products with field information. The UAV multispectral imagery data were captured in four agricultural plots and used as ground-truth information. The four plots were representative of different levels of crop damage and types of cultivated rice. To assess the matching of information between UAV images and satellite images, we calculated the proportion of damage in each square of a $10 \times 10 \mathrm{~m}$ mesh co-registered with Sentinel-2 pixels. Then, we selected Sentinel- 2 images close to the date of UAV imagery and calculated the Normalized difference vegetation index (NDVI), explained in more detail in the following sections. To reduce noise in the analyses, the $10 \mathrm{~m}$ pixels that were not purely of rice crops were removed. We then built a model that related the proportion of damage assessed by UAV imagery to the Sentinel-2 NDVI data. We used the fitted relationship to extrapolate rice damage to the whole Sentinel-2 Delta Ebro image. The prediction maps were validated with independent damage information derived from field observations at the plot level. The following sections explain the entire procedure in more detail.

\subsection{Sentinel-2 Imagery}

We used free Sentinel-2 imagery that had already been atmospherically-corrected by European Space Agency's (ESA) Sen2Cor algorithm (Level-2A) [34]. We selected sixteen available cloud-free images from April to August 2017 corresponding to the Sentinel-2 31TCF zone: April 3, April 6, May 6, May 16, May 23, May 26, June 12, June 15, June 22, July 2, July 5, July 12, August 4, August 14, August 21, and August 24. We calculated the Normalized Difference Water Index (NDWI) for every date. 
NDWI was proposed by McFeeters in 1996 to delineate the open water features by means of the green and NIR wavelengths:

$$
N D W I=\frac{G R E E N-N I R}{G R E E N+N I R}
$$

The water surfaces have positive values, while the surface of the earth and vegetation have 0 or negative values. This NDWI time series was used to identify water channels near the fields to allow later selection of pure rice crops squares, as is explained in Section 3.4. The August 24 image was the one selected to quantify the maximum crop damages, because it matches the highest season of Western Swamphen activity and is the available image close to the capture date of UAV images. Some small clouds and their shadows present in this image were manually removed by screen digitization. We calculated NDVI for the August 24 Sentinel-2 image, and we refer to this as Sentinel2-NDVI.

\subsection{UAV Imagery Adquisition}

High resolution image data were collected using a quadcopter (UAV Phantom 3 from DJI) [35]. This light weight (1280 g) UAV is capable of autonomous waypoint flight following a preplanned route (Figure 3). A Parrot SEQUOIA multispectral camera was installed in the quadcopter, with four 1.2 megapixel monochrome sensors that collected global shutter imagery along four discrete spectral bands: green (center wavelength (CW): $550 \mathrm{~nm}$; bandwidth (BW): $40 \mathrm{~nm}$ ), red (CW: $660 \mathrm{~nm}$; BW: $40 \mathrm{~nm}$ ), red edge (CW: $735 \mathrm{~nm}$; BW: $10 \mathrm{~nm}$ ), and near infrared (CW: $790 \mathrm{~nm}$; BW: $40 \mathrm{~nm})$. The horizontal $(\mathrm{H})$, vertical $(\mathrm{V})$, and diagonal (D) fields of view (FOV) of the multispectral camera were $61.9^{\circ}$ (HFOV), $48.5^{\circ}$ (VFOV), and $73.7^{\circ}$ (DFOV), respectively, with a focal length of $4 \mathrm{~mm}$. The camera was bundled with an irradiance sensor to record light conditions in the same spectral bands as the multispectral sensor ISO (International Organization for Standardization) value and exposure time was set to automatic. The setting of every captured image is saved in a text metadata file with the irradiance sensor data. All this information was taken into account during the preprocessing stage to obtain reflectance values for the final multispectral product.

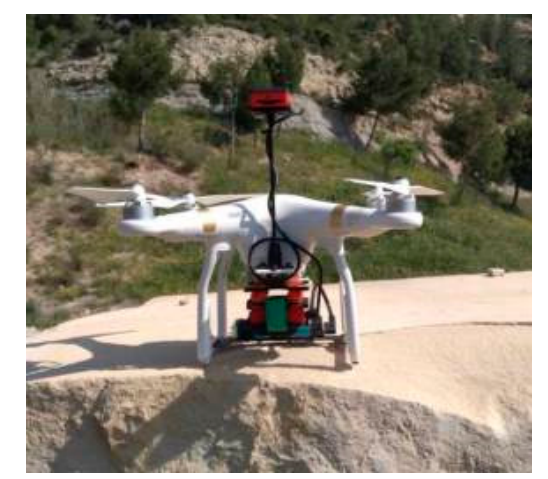

Figure 3. Phantom 3 DJI with the Parrot SEQUOIA camera and irradiance sensor, used for the aerial survey.

UAV imagery was captured at four different agricultural plots (Figure 1). These four plots were selected with expert criteria for their representativeness in terms of levels of damage and type of cultivated rice and were all near the potential harvesting date. After initial field inspection by rangers, Plots 1, 2, and 4 appeared to present damages causing loss of rice cover in many areas, showing a variety of spatial patterns (both scattered and aggregated). Initial inspections of Plot 3 did not detect damage to the rice crop. The four plots may have been treated with a variety of agricultural treatments in previous months, and plot 4 included a different rice variety. Images were captured during the same day in consecutive hours before and after the noon. The flying altitude was $80 \mathrm{~m}$ for three plots with an average GSD (Ground Sample Distance) of $8 \mathrm{~cm}$ and an average area of 12 ha. The flying altitude for the fourth flight was of $100 \mathrm{~m}$ with an average GSD of $10 \mathrm{~cm}$. The flight speed was $5 \mathrm{~m} / \mathrm{second}$ with $80 \%$ forward and sideways overlap. Images were captured on 17 August 2017, a few days before 
the harvest, when the maximum crop damages could be observed. Before each flight, images of the Sequoia calibration panel (by AIRINOV) were captured in order to apply radiometric calibration and corrections from reference reflectance maps. Crop monitoring requires accurate calibration [36], therefore, we ensured application of the same methodology in all the flights: the target is level with the ground and not at an angle; the target is not affected by shadows or reflections of eventual surrounding objects; and the panel images are taken around 1 meter away from the panel and not facing the sun. Several images were taken before the flight to ensure we obtained images with lighting conditions as similar as possible to the ones during the flight. At the moment of application of the radiometric calibration we chose the most appropriate panel picture for each flight.

Three of the plots were totally surveyed, corresponding to areas between 3 and 5 ha each, and the fourth plot had a total area of $194.60 \mathrm{ha}$, and a representative surface of $17 \mathrm{ha}(8.7 \%)$ was surveyed.

\subsection{UAV Imagery Processing}

UAV data was processed into a multispectral orthomosaic with Pix4Dmapper Pro 4.2 following the "Ag Multispectral" template. Pix4D is based on the Structure from Motion algorithms and also integrates computer vision techniques with photogrammetric algorithms $[37,38]$ to obtain high accuracy in aerial imagery processing $[39,40]$. Pix4Dmapper Pro computes key points in the single images and uses them to find matches between images. From these initial matches, the software runs several automatic aerial triangulation steps, bundle bloc adjustments, and camera self-calibration steps iteratively until optimal reconstruction is achieved [29]. Then, a densified point cloud is generated to obtain a highly detailed digital surface model (DSM) that will be used to generate the final orthomosaics and reflectance maps for every plot (Figure 4).

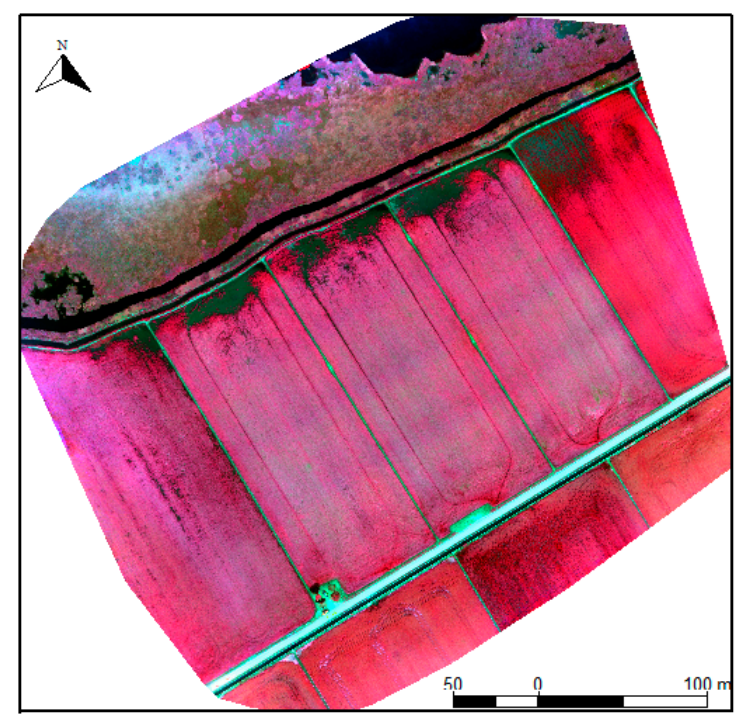

Figure 4. UAV color infrared composition: NIR (near-infrared) + RED + GREEN; for one of the agricultural plots (pixel resolution: $10 \mathrm{~cm}$ ). Damages caused by Western Swamphen are shown in the northern part of the rice plots (dark colors correspond to water without rice plants). In the upper part of the image there is an important wetland, which is differentiated by a more dispersed wet vegetation zone and a fragment of water body (with dark-blue color). Surveyed plot number 1.

The reflectance maps were built by applying radiometric calibrations and corrections. First, radiometric calibration was performed by using the calibration target images that enable one to have an absolute reference of radiometry for that day, and finally makes it possible to compare data coming from several flights. Second, the radiometric corrections "Camera and Sun irradiance" aimed at correcting terrain reflectance was also applied. Within this, the Pix4Dmapper first uses the values of ISO, aperture, shutter speed, sensor response, and optical system and vignetting registered in the text metadata 
files (EXIF and XMP tags) for every single photogram to correct the camera. Then, the incoming sunlight irradiance is corrected with the information provided by the sun irradiance sensor. This sensor provides information on the light conditions during the flight within the same spectral bands as the one captured by the multispectral sensor and it is registered in the same text metadata files described above. This "Camera and Sun irradiance" correction normalizes the images captured during the flight and, thus, allows one to compare images taken in different illumination conditions. Pix4Dmapper applies this calibration and correction process to every single photogram just before it achieves the final reflectance orthomosaic for every spectral band (Figure 3). We have calculated the mean error in $x-y$ coordinates by means of geolocation four-points-per-survey through screen digitalization in the UAV final orthomosaic and in the 1:1000 official orthophotos. We have calculated the difference between both points sets and the mean error in $\mathrm{x}$ and $\mathrm{y}$ is $0.56 \mathrm{~m}$ and $1 \mathrm{~m}$, respectively.

We calculated the NDVI index for the UAV images. The normalized difference vegetation index NDVI [41] quantifies vegetation by measuring the difference between near-infrared (NIR), which vegetation strongly reflects, and red light $(\mathrm{R})$, which vegetation absorbs with:

$$
N D V I=\frac{N I R-R}{N I R+R}
$$

NDVI ranges from -1 to +1 ; negative values in wetland habitats are usually related to water surfaces, while positive values close to 0 represent low green vegetation cover and values close to 1 are usually associated with vegetation with dense green foliage. In this work, the NDVI index allowed us to identify no-greenery vegetation pixels, with or without water pixels, and also low greenery pixels, representing the damages caused by Western Swamphen in rice crops. It has been previously found with images from Sentinel-2 [42] that the use of vegetation indices improves the results of crop classifications over the use of the respective individual bands.

A simple Jenks classifier was applied separately for every flight and provided the highest discrimination ability to create a binary green vegetation/no-vegetation map (Figure 5). The Jenks classifier determined a class break value that produced two natural groupings by minimizing each class's average deviation from its mean, while maximizing each class's deviation from the other class's mean. The thresholds to separate the non-vegetation from green vegetation with NDVI data were different for each surveyed plot, taking values between 0.56 and 0.79 , depending on the variety and the state of vegetation development of each plot.

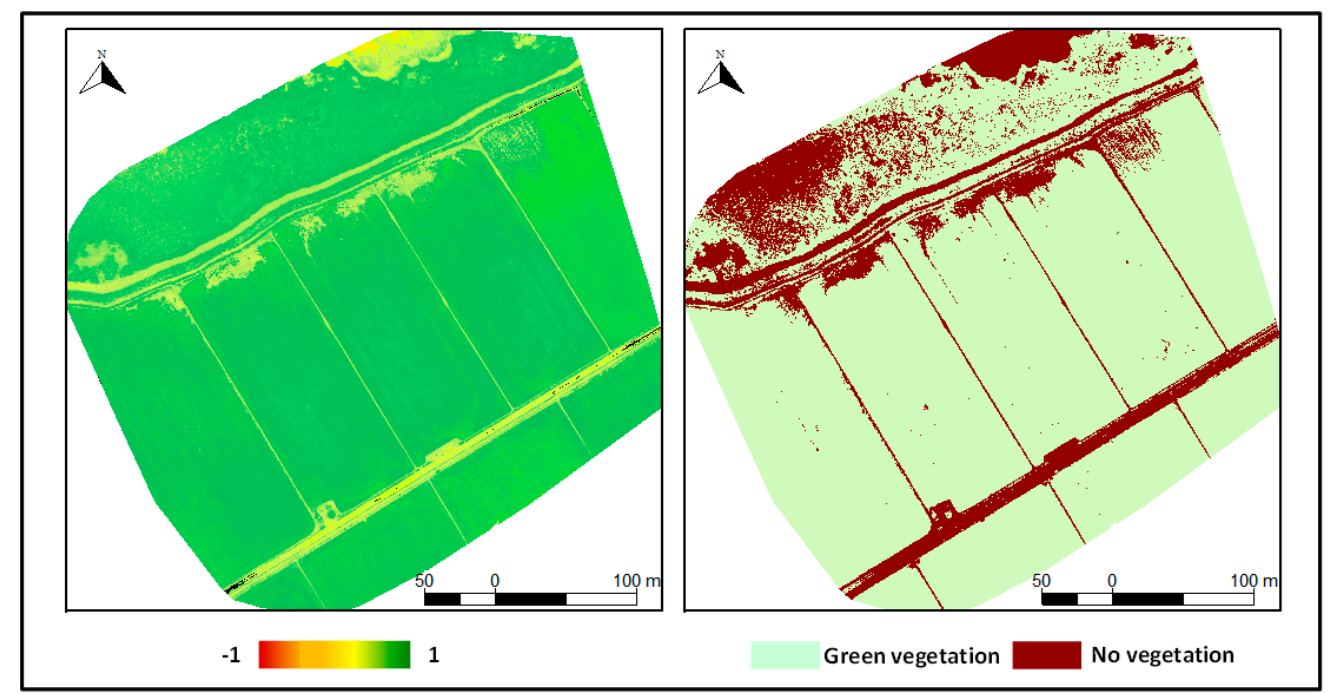

Figure 5. Surveyed plot 1: UAV-NDVI index on the left, and non-vegetation mask on the right. It is possible to appreciate an important lack of vegetation in the north part of the plot and some scattered damages in the middle and in the south part. 
A $10 \times 10 \mathrm{~m}$ mesh was created for each surveyed plot from the August 24 Sentinel-2 image pixels. The proportion of water and the proportion of non-vegetation for every $10 \times 10 \mathrm{~m}$ square was calculated by obtaining a proportion of no-greenery vegetation for both indices (Figure 6). Values near 1 indicated a higher proportion of damage and values near 0 indicate lower or null proportion of damage. From now on we will refer to this $10 \times 10 \mathrm{~m}$ information as UAV-crop damage.

\subsection{Selecting Pure Rice Crops Squares}

In order to reduce noise from the analyses, we selected the $10 \times 10 \mathrm{~m}$ squares that completely contained rice crops (in contrast with other pixels that also contain other land uses, such as rural tracks) (Figure 6). Two sources of information were used to make this selection: (1) Agricultural Plot Map from the Catalan government, henceforthm SIGPAC (Spanish acronym of Geographical Information System of Agricultural Plots); and (2) all the available April-August 2017 Sentinel-2 cloud free images. SIGPAC is a free downloadable cartography provided by the government of Spain, which is renewed on a year basis. Pixels that were totally or mostly within a plot of "Arable Earth" category were selected. However, this cartography scale does not include all water channels. For this reason, Sentinel-2 imagery was also used to identify them. Since the water is not distributed equally throughout the year on all channels, we selected the maximum NDWI value for every pixel of the NDWI time series described in Section 3.1 to identify the maximum water that can flow at any time of the year. Finally, with the two sources we computed a water channel mask and we applied it to all UAV-crop damage and Sentinel2-NDVI data. In addition, it was necessary to filter some pixels manually that the described methodology had not recognized (especially in the sampled plots).

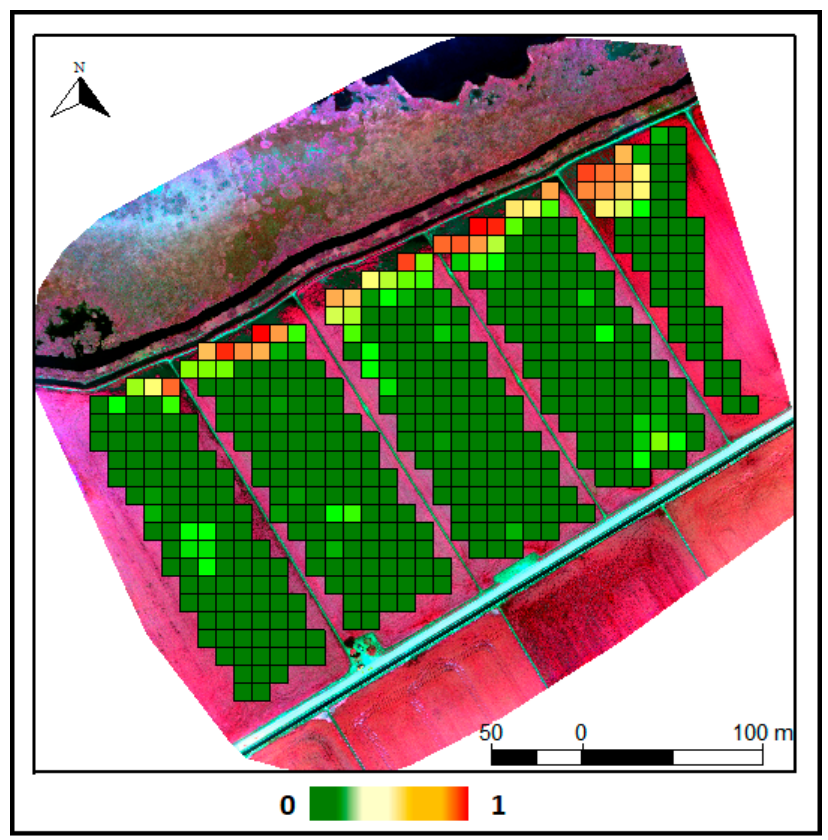

Figure 6. Selected $10 \times 10 \mathrm{~m}$ cells (co-registered with Sentinel-2 pixels) for surveyed plot number 1. The image shows the non-vegetation ratio calculated with UAV images for every Sentinel-2 pixel used in the model calibration, from 0 to 1 , where 0 represents green vegetation, or non-damage, and 1 non-vegetation proportion, or damaged. The background image corresponds to the UAV infrared composition image. It is possible to detect some important damages due to an important lack of vegetation in the north of the plot, and some pixels with a lower damage ratio due to scattered damage in the rest of the plot. 


\subsection{Calibrating Sentinel2 with UAV-Crop Damage Information}

We calibrated Sentinel2-NDVI with UAV-crop damage information for the $10 \times 10 \mathrm{~m}$ cells. We used a generalized linear mixed effect model (GLMM) that predicted the proportion of damage as a function of NDVI value derived from Sentinel, and incorporated each plot as the random factor. We adopted a logistic regression with a logit link function (Equation (3)).

$$
\ln \left(\frac{U A V_{\text {damage }_{\text {ratio }}}}{1-U A V_{\text {damageratio }}}\right)=a+b * \text { Sentinel } 2 \text { NDVI }
$$

This logistic regression type was chosen because it allowed us to better fit values that cannot range below 0 or above 1 . The mixed model regression is suitable to use when some of the observations share common sampling units that can gather some of the variance not directly explained by the fixed factors. In this case each of the agricultural plots may hold differences in rice variety and phenology, seed time, or irrigation conditions, but similarities in each of the cells within each plot. The variability of plot features is included through the random factor of the mixed model.

We checked for model residuals distribution through a fitted residual plot, and we evaluated model goodness-of-fit through the marginal $\mathrm{R}^{2}$ (explained by fixed factors), conditional $\mathrm{R}^{2}$ (explained by both fixed and random factors), and the Root Mean Square Error (RMSE). The model was validated by applying a cross-validation method using $80 \%$ of observations for calibration and $20 \%$ for testing. Predicted values for test observations were compared to observed values with a linear regression obtaining an adjusted r-squared and a test RMSE. To minimize the bias of the subsampling test data, we ran a 10-fold random subsampling cross-validation and we finally obtained an average adjusted r-squared and RMSE for the ten sub-validations.

\subsection{Crop Damage Evaluation at the Plot Level: Translating the Final Models into Useful Products for Landscape Managers}

The management unit for the landscape managers is the SIGPAC agricultural plot. The payments for damages are granted based on damage that occurred in each agricultural plot and quantified in hectares, so our goal was to provide a measure of damage per SIGPAC plot. We assume that the damages that cause large loss of vegetation, as the ones observed in the north of the surveyed plot number 1 (from Figure 4 to Figure 6), are the minority, and the majority of damages represent a small proportion of the $10 \mathrm{~m}$ Sentinel-2 pixel (check photographs in Figure 2). We also observe that most parts of $10 \mathrm{~m}$ pixels in the whole Delta have an estimated damage ratio under $1 \%$ that could not be considered as real damage caused by Wester Swamphen. Thus, we needed to identified pixels with significant crop damage that would be caused by the bird and then the final damage map would correspond to the sum of the full pixel surfaces, with significant damage values for each agricultural plot.

First, we needed to identify this significant crop damage threshold. To proceed with this identification, we tested different thresholds: $4 \%, 6 \%, 8 \%, 10 \%$, and $20 \%$. The selection of these thresholds took into account a compromise between level of significant damage $(>1 \%)$ and number of damaged pixels selected within every threshold. Low thresholds selected a great number of pixels but may have included pixels that were not actually damaged by birds. Instead, high thresholds selected only pixels with large loss of vegetation, avoiding also damaged pixels without large loss of vegetation. Then, the sum of the damaged pixels for each threshold in each surveyed plot was calculated. Finally, this different estimations at the agricultural plot level were validated $[30,43]$ with ground information from Rangers Service from the Catalan government, which follows an established protocol to assess crop damage in the field. Once a farmer has detected some damage caused by the Western Swamphen, he claims the assessment on the field by the Rangers Service to quantify damages and receive the corresponding payments. This assessment is performed on the ground, next to the affected plot, and it is only based on expert criteria. It does not constitute an exact quantification of the damages but it offers an approximate value to evaluate models' predictions. 


\section{Results}

The four surveyed plots showed different ranges of UAV-crop damages and Sentinel2-NDVI at a $10 \mathrm{~m}$ pixel level. Plot number 1 and 2 held a wide UAV-crop damage range ( 0 to 0.97 , and 0 to 0.93 , respectively, Table 1), whereas the UAV-crop damage range in plot number 3 was between 0 and 0.36 , and the crop UAV-crop damage for plot number 4 was always under 0.04 . This indicated that plots 1 and 2 have larger parts with loss of vegetation, while the damage in crops 3 and 4 are smaller and dispersed throughout the plot. Sentinel2-NDVI range of values also showed clear differences: plot 1 had the widest range ( 0.32 to 0.78$)$, plot number 2 ranged between 0.38 and 0.74 , plot number 3 had Sentinel2-NDVI ranges between 0.38 and 0.95 , and plot 4 showed a small range above 0.5 , specifically between 0.52 and 0.78 .

Table 1. Ranges of UAV-crop damage and Sentinel2-NDVI (Normalized difference vegetation index) per pixel for all the $10 \mathrm{~m}$ pixels in the surveyed plots.

\begin{tabular}{ccc}
\hline Plots & UAV-Crop Damage Range & Sentinel2-NDVI Range \\
\hline 1 & $0-0.97$ & $0.32-0.78$ \\
2 & $0-0.93$ & $0.38-0.74$ \\
3 & $0-0.36$ & $0.38-0.95$ \\
4 & $0-0.04$ & $0.52-0.78$ \\
\hline
\end{tabular}

The selected fitted generalized linear mixed model between UAV-damage ratio and Sentinel2-NDVI achieved good model adjustments, with a RMSE of 0.054 (Table 2). The random effect of the variable "surveyed plot" appeared significant $(<0.001)$, meaning that the intercept of the relationships between Sentinel2 and UAV-damage differed by plot. The model presented a goodness of fit explained by fixed effects (Sentinel2-NDVI) of $48 \%$, described as marginal $\mathrm{R}^{2}$ in Table 2, and explained by both fixed and random (surveyed plot) effects of $81 \%$, described as conditional $\mathrm{R}^{2}$ also in Table 2 . The cross-validation decreased its prediction ability in comparison to the full calibrated model, but still achieved relevant performances, with an average of $57 \%$ in the regression between observed and predicted values and a RMSE of 0.102 (Table 2). The Sentinel2-NDVI index exerted a negative influence in predicting observed damage: an increase in Sentinel2-NDVI values decreases the proportion of Western Swamphen damage described by UAV (Figure 7).

Table 2. Goodness-of-fit estimate values for the fitted model and an average of 10 repetitions of model validation, with $20 \%$ of the dataset randomly selected for each repetition represented by the Marginal, Conditional and Adjusted coefficient of determination $\left(\mathrm{R}^{2}\right)$ and the Root Mean Square Error (RMSE).

\begin{tabular}{ccccc}
\hline \multicolumn{2}{c}{ Model Goodness-of-Fit Estimate } & \multicolumn{2}{c}{$\begin{array}{c}\text { Model Validation (10-Fold } \\
\text { 20\% Dataset Validation) }\end{array}$} \\
\hline Marginal $\mathbf{R}^{\mathbf{2}}$ & Conditional $\mathbf{R}^{\mathbf{2}}$ & RMSE & Adjusted $\mathbf{R}^{\mathbf{2}}$ & RMSE \\
\hline 0.481 & 0.814 & 0.054 & 0.572 & 0.102 \\
\hline
\end{tabular}

The model predicted low values of damage proportion, close to 0 , in most parts of the pixels with Sentinel2-NDVI values above 0.55 (blue line in Figure 7). NDVI values under 0.55 predicted damages ratios from 0.05 to 1 (corresponding to $5 \%$ and $100 \%$ respectively). Most pixels had a damage ratio under 0.20 , decreasing considerably the number of pixels with damage ratios above $25 \%$. However, in contrast to what was expected, there are some pixels with damages between 0.12 and mostly up to 0.25 , with relatively high Sentinel-NDVI values, specifically with values between 0.6 and 0.8 (Figure 7), most of them belonging to plot 3 . 


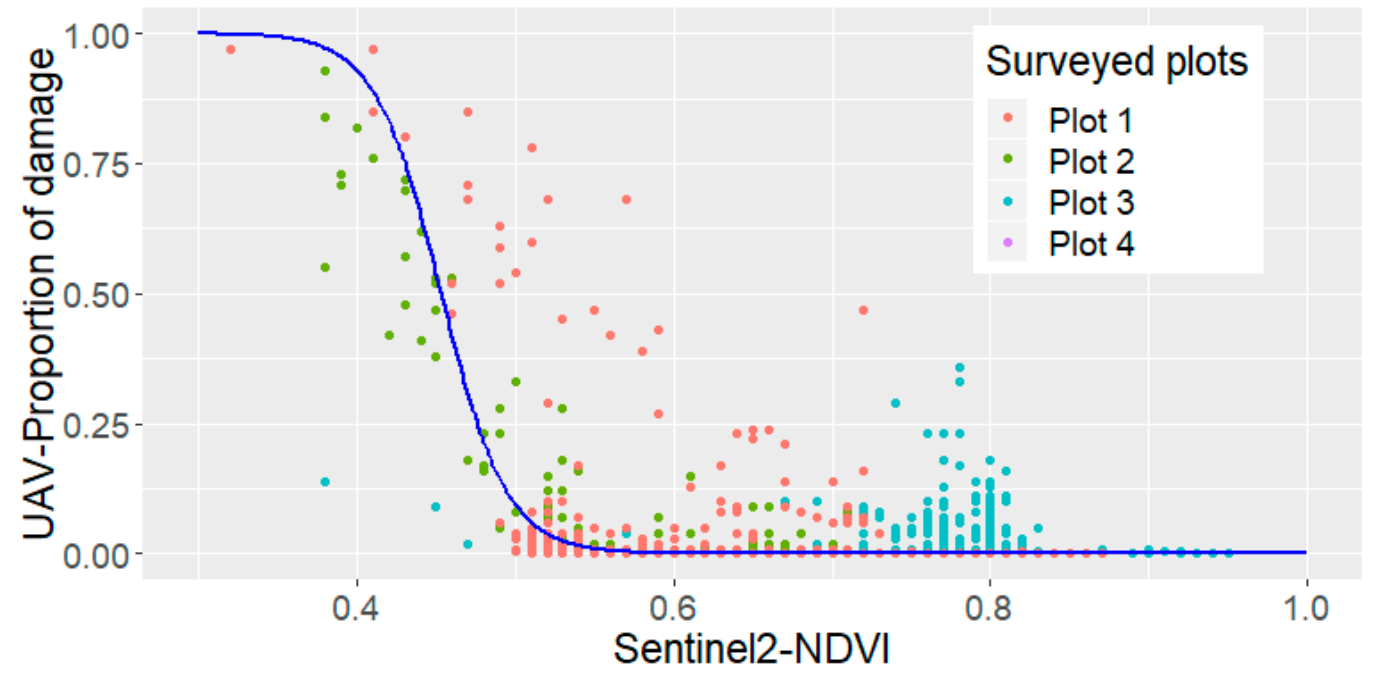

Figure 7. Scatterplot showing the relationships between UAV-crop damages and Sentinel2-NDVI. The blue line shows the best-fit model. Every surveyed plot is represented in different colors. Plot 4 (violet color) has got very low UAV-crop damages and high Sentinel2-NDVI values, so it is barely visible on the graph.

We applied the resulting model to the whole August 24 Sentinel-2 NDVI product for the Ebro Delta. The final map informed about proportion of damage per pixel with values between 0 and 1 (Figure 8). The predicted crop damage map identified the pixels with large areas of no-vegetation, with colors from yellow to red in Figure 8. Most part of the Delta had values close to 0, represented by green colors (Figure 8).
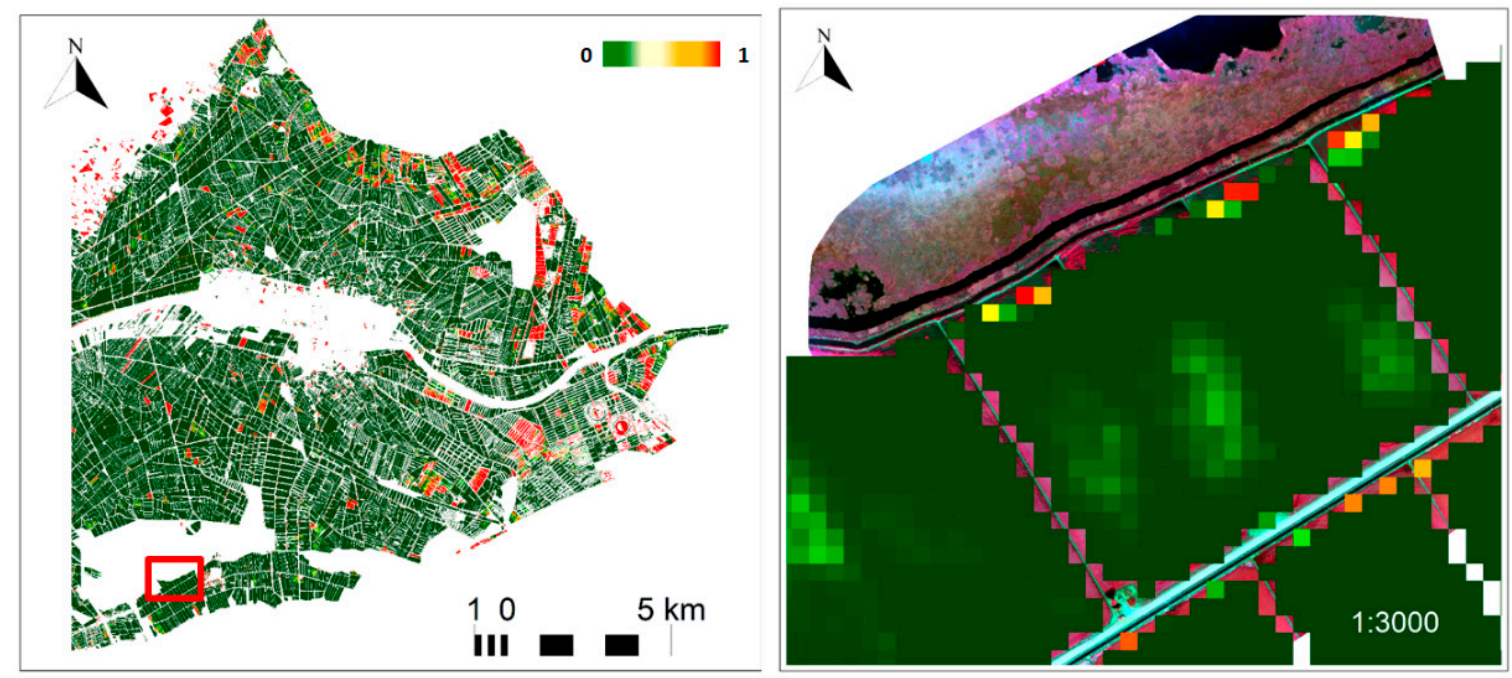

Figure 8. Predicted crop damage according to the NDVI model for the whole Delta (left) and a zoom to surveyed plot 1 , in the south west of the Delta (right). Both figures take values from 0 to 1 , colored from green to red, respectively, representing a pixel ratio damage from 0 to 1 .

Finally, we applied the defined damage thresholds $(4 \%, 6 \%, 8 \%, 10 \%$, and $20 \%)$ to calculate the estimated agricultural plot damage (Figure 9). Once a pixel has a predicted damage above this threshold, the entire pixel is accounted as damaged. Pixels above these thresholds represented 13\%, $12 \%, 11.6 \% 11.2 \%$, and $10 \%$ of the total predicted surface, respectively. Therefore, damages ratios under $4 \%$ represent the majority of the Delta pixels ( $87 \%$ of total crop pixels).

The validation of the different thresholds with ground information from the Rangers Service showed an underestimation of damages in plots 1 and 2 (Table 3), even in the lowest damage ratio 
threshold. For plot 1, the largest threshold of damage assessed (20\%) included some of the pixels with higher damage identified visually (Figure 9, northern part). On the contrary, and unexpectedly, the lowest threshold (4\%) did not include all the high damage pixels identified visually, but it is also important to note that this threshold correctly identifies the scattered damages in the center of the plot. In plot 3, predicted damages are virtually null, similar to the information gathered by the Rangers Service (Table 3). Finally, there is a slight overestimation of predicted damages in plot 4, although as the damage threshold per pixel rises, the total value of the plot is closer to the quantification by the Rangers Service (Table 3), being the $20 \%$ threshold, which is slightly lower than Rangers Service quantification.

Table 3. Model validation at the plot level for the four surveyed plots with ground level Rangers Service information. This table shows the plot surface (ha) for each surveyed plot from the SIGPAC (Geographical Information System of Agricultural Plots from Catalan Government) plot surface information, the Rangers Service damage quantification, and predicted damage per agricultural plot at different thresholds, corresponding to different $\%$ of damage per pixel $(4 \%, 6 \%, 8 \%, 10 \%$, and $20 \%)$.

\begin{tabular}{cccccccc}
\hline \multirow{2}{*}{ Plot Code } & \multirow{2}{*}{$\begin{array}{c}\text { Plot Surface } \\
\text { (ha) }\end{array}$} & $\begin{array}{c}\text { Rangers } \\
\text { Service (ha) }\end{array}$ & \multicolumn{4}{c}{$\begin{array}{c}\text { Predicted Damage per Agricultural Plot } \\
\text { (ha) at Different Thresholds }\end{array}$} \\
\cline { 4 - 8 } & & & $\mathbf{> 4 \%}$ & $\mathbf{> 6 \%}$ & $\mathbf{> 8 \%}$ & $\mathbf{> 1 0 \%}$ & $\mathbf{2 0 \%}$ \\
\hline $\mathbf{1}$ & 4.53 & 1.09 & 0.47 & 0.29 & 0.16 & 0.11 & 0.06 \\
$\mathbf{2}$ & 5.16 & 0.66 & 0.52 & 0.47 & 0.45 & 0.42 & 0.37 \\
$\mathbf{3}$ & 3.37 & No damage & 0.01 & 0.01 & 0.01 & 0.01 & 0.01 \\
$\mathbf{4}$ & 194.60 & 2.19 & 2.51 & 2.43 & 2.36 & 2.35 & 2.18 \\
\hline
\end{tabular}

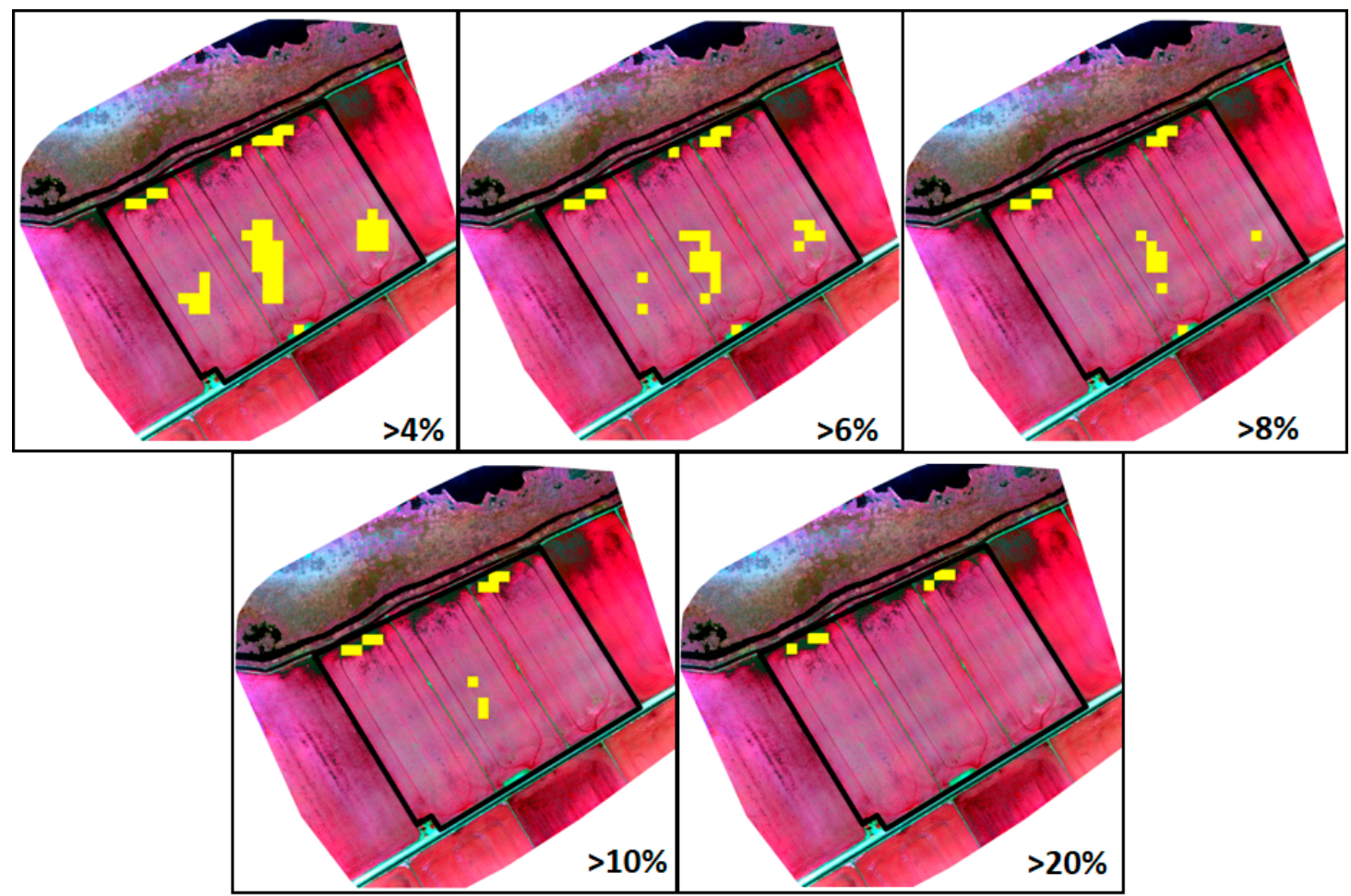

Figure 9. The yellow pixels show the selected damaged pixels at different thresholds of damages $(4 \%, 6 \%, 8 \%, 10 \%$, and $20 \%)$ in plot 1 . There are 6 pixels with damage ratios above $20 \%, 11$ pixels with damage ratios above $10 \%, 16$ pixels with damage ratios above $8 \%, 29$ pixels with damage ratios above $6 \%$, and 47 pixels with damage ratios above $4 \%$. 


\section{Discussion}

The quantification of Western Swamphen crop damage is a big challenge due to its fine grained patterns. The methodology developed in this work, and especially the results and validation of the regression model, appear promising for quantifying this type of damage with Sentinel-2 imagery. The prediction of damages at the agricultural plot level with a previous filter of pure crop pixels is also promising. Previous analyses including pixels containing water channels, roads, pathways, or other land covers showed weaker relationships and major errors (not shown).

The model can more-easily predict damages that produce important loss of vegetation, and it has more difficulty in identifying the less-intense and scattered damages, i.e., less than $25 \%$ of damage per $10 \mathrm{~m}$ pixel. The scattered damages are able to be detected from UAV but are more difficult to appreciate at Sentinel-2 level because the NDVI values in these pixels remains high. The model presents important limitations to predict damages that only affect the rice grains without decreasing plant vigorousness, and even more if the damaged areas are covered by some type of vegetation, such as algae, which also produces high values of greenery. These types of damages are also arduous to detect with UAV multispectral imagery.

The Sentinel-2 $10 \mathrm{~m}$ resolution resulted in consistent relationships with UAV information, since the fitted model achieved a good adjustment, although differences appeared among the four surveyed plots that may decrease the adjustment in the cross-validation. We assume that there are not important calibration differences between flights that could influence these results because we have ensured we applied the same methodology to capture calibration panels pictures and we also assume that the reflectivity is quite similar in the four flights due to the hour of the flights (few hours before and after the noon) and the date of the year (August 17th) in the Delta Ebro region. These differences might be related mainly to the differences in the pressure exerted by the species on the crop, rice variety, or agricultural treatments, or due to minor differences in phenology state, but these effects must be minimal because all fields were close to being harvested. These differences increase the uncertainty of the model, but the mixed generalized model is appropriate because it allows incorporation of such differences between crops as a random factor and derivation of one single model for the whole Delta area. The use of a single model for the whole Delta that incorporates the intrinsic variability of rice crops facilitates the transfer of the methodology to the landscape managers in order to use an objective methodology to quantify damages and define economic compensation strategies.

The Sentinel-2 $10 \mathrm{~m}$ information resolution also allows a promising prediction of damages at the agricultural plot level. The selection of an adequate significant damage threshold shows good potential for identifying scattered damages at this scale. Considering a low damage ratio pixel as a whole affected pixel seems to counteract the difficulties of detecting scattered damages at the $10 \mathrm{~m}$ pixel level. This may be reasonable, because according to expert knowledge, scattered damages may show aggregated patterns, therefore, close to some of the detected damages there may be damages that effect rice production but produce low NDVI decrements that are very difficult to detect, even with UAV. The filtering of agricultural pure pixels may produce an underestimation of damages in pixels with important loss of vegetation because the majority of pixels with large loss of vegetation are near agricultural crop edges next to roads and water channels, and some of them they may have been excluded from the analysis, meaning they are not accounted for in the total damaged surface per agricultural plot. On the other hand, automatic pixel filtering also has other limitations in the other direction-there may also be an overestimation of damages in pixels with a small fraction of other uses that have not been filtered by the automatic methodology.

One of the highlights of this project has been the use of multispectral information. The NIR channel information from UAV allowed us to describe the characteristics of the vegetation, which are not well described by using the visible spectrum. At the same time, multispectral information enabled the generation of products more related to the multispectral medium resolution information derived from satellites as Sentinel-2 or Landsat. Previous works applying calibration of multispectral remote sensing measurements from UAV are very few and are aimed at quantifying other ecosystem attributes, 
such as fire severity [30,31]. In these cases, correlations between UAV and medium resolution remote sensing imagery have been found to be higher than the ones presented in this work. This may be because the damages caused by large forest fires are more apparent and visually-identifiable from medium resolution remote sensors than the Western Swamphen damages.

This calibration can be used to estimate damages in Sentinel images in other temporal or spatial contexts. Further validations are fostered in order to better test the capability to properly predict these kinds of damages. However, it is important to note that there may be other animal species that produce similar damages as the ones produced by the Western Swamphen. Moreover, images might detect other agronomic variations of the crops themselves due to diseases, germination problems, environmental variations, etc., with similar responses to the damage produced by animals. For this reason, a complementary expert identification of the plots that have been damaged by this species will generally be required in order to correctly estimate the final cause of damage to the rice crop.

Finally, we conclude that the models in this work improve the cost-efficiency of the quantification of Western Swamphen damage in large rice crop areas, especially in terms of objectivity. However, the methodology presents some weakness that should be addressed in the future to enhance the robustness of the models. We believe that the main points to consider could be the following:

- Exploring other UAV vegetation indices that could improve the regressions with Sentinel-2 imagery in order to better discriminate scattered damages, and also identify damaged spots that have been covered with algae or other vegetation and damages that only affect the rice grains.

- Analyzing in greater depth the potential relationship between different rice types and the detectable damage. Different varieties of rice are cultivated, each one with different morphology, and these differences could affect the detectability of the damage.

- Analyzing the effects, including the information from neighboring pixels.

- Improved mapping of water channels, roads, and pathways cartography in order to extract easily the Sentinel-2 pixels with these land covers.

- Working on a reliability map aimed at offering the land manager proper information about the real quality of the final model at the plot level.

\section{Conclusions}

We have introduced here a new methodology to use Sentinel-2-based NDVI as a proxy to quantify rice crop plot damages caused by Western Swamphen. Furthermore, we have shown how satellite-derived crop damage estimates can be calibrated by using UAV multispectral imagery onboard a low-cost unmanned vehicle. Our approach allows estimation of rice crop damage at large scales with relatively good accuracy. This approach offers a good, cost-effective alternative to high resolution imagery from more expensive, finer-resolution commercial satellites. Following works on knowledge transfer will improve the preparation of quality maps that could allow assessment with a greater accuracy of crop damages. Providing information about the quality of the products and their limitations is crucial for a useful knowledge transfer process.

Author Contributions: Conceptualization, G.B. and L.B. Formal analysis, M.P. Funding acquisition, R.G. Investigation, M.P. and L.B. Methodology, M.P. Project administration, G.B., R.G., and L.B. Resources, J.B. Supervision, L.B. Validation, A.C. Writing-review and editing, M.P., A.D., and L.B.

Funding: This research was funded by Ministry of Territory and Sustainability, Government of Catalonia.

Acknowledgments: We thank the Parrot Innovation Grant for the provision of the multispectral camera and the use of the Pix4D software. We also thank the Ebro Delta Natural Park and the Rangers Service of the Catalan Government for the facilities offered during the capture of UAV images.

Conflicts of Interest: The authors declare no conflict of interest. 


\section{References}

1. Barua, M.; Bhagwat, S.A.; Jadhav, S. The hidden dimensions of human-wildlife conflict: Health impacts, opportunity and transaction costs. Biol. Conserv. 2013, 157, 309-316. [CrossRef]

2. Redpath, S.M.; Young, J.; Evely, A.; Adams, W.M.; Sutherland, W.J.; Whitehouse, A.; Amar, A.; Lambert, R.A.; Linnell, J.D.C.; Watt, A.; Gutiérrez, R.J. Understanding and managing conservation conflicts. Trends Ecol. Evol. 2013, 28, 100-109. [CrossRef]

3. Moreno-Opo, R.; Pique, J. Reconciling the conservation of the purple swamphen (Porphyrio porphyrio) and its damage in Mediterranean rice fields through sustainable non-lethal techniques. PeerJ 2018, 1-19. [CrossRef] [PubMed]

4. Karanth, K.K.; Gopalaswamy, A.M.; Prasad, P.K.; Dasgupta, S. Patterns of human-wildlife conflicts and compensation: Insights from Western Ghats protected areas. Biol. Conserv. 2013, 166, 175-185. [CrossRef]

5. Agarwala, M.; Kumar, S.; Treves, A.; Naughton-Treves, L. Paying for wolves in Solapur, India and Wisconsin, USA: Comparing compensation rules and practice to understand the goals and politics of wolf conservation. Biol. Conserv. 2010, 143, 2945-2955. [CrossRef]

6. Villero, D.; Pla, M.; Camps, D.; Ruiz-Olmo, J.; Brotons, L. Integrating species distribution modelling into decision-making to inform conservation actions. Biodivers. Conserv. 2017, 26, 251-271. [CrossRef]

7. López-Bao, J.V.; Frank, J.; Svensson, L.; Åkesson, M.; Langefors, Å. Building public trust in compensation programs through accuracy assessments of damage verification protocols. Biol. Conserv. 2017, 213, 36-41. [CrossRef]

8. Lane, S.J.; Azuma, A.; Higuchi, H. Wildfowl damage to agriculture in Japan. Agric. Ecosyst. Environ. 1998, 70, 69-77. [CrossRef]

9. Pernollet, C.A.; Simpson, D.; Gauthier-Clerc, M.; Guillemain, M. Rice and duck, a good combination? Identifying the incentives and triggers for joint rice farming and wild duck conservation. Agric. Ecosyst. Environ. 2015, 214, 118-132. [CrossRef]

10. IUCN Redlist; Birdlife International. Gavia Stellata: European Red List of Birds; Birdlife International: Cambridge, UK, 2015; ISBN 9789279474507.

11. Tucker, M.; Heath, M.F.; Tomialojc, L.; Grimmett, R. Birds in Europe: Their Conservation Status; Birdlife Conservation: Cambridge, UK, 1994; ISBN 10: 0946888299/ISBN 13: 9780946888290.

12. Kwak, Y.; Shrestha, B.B.; Yorozuya, A.; Sawano, H. Rapid Damage Assessment of Rice Crop after Large-Scale Flood in the Cambodian Floodplain Using Temporal Spatial Data. IEEE J. Sel. Top. Appl. Earth Obs. Remote Sens. 2015, 8, 3700-3709. [CrossRef]

13. Möller, M.; Gerstmann, H.; Gao, F.; Dahms, T.C.; Förster, M. Coupling of phenological information and simulated vegetation index time series: Limitations and potentials for the assessment and monitoring of soil erosion risk. Catena 2017, 150, 192-205. [CrossRef]

14. Navrozidis, I.; Alexandridis, T.K.; Dimitrakos, A.; Lagopodi, A.L.; Moshou, D.; Zalidis, G. Identification of purple spot disease on asparagus crops across spatial and spectral scales. Comput. Electron. Agric. 2018, 148, 322-329. [CrossRef]

15. Inglada, J.; Arias, M.; Tardy, B.; Hagolle, O.; Valero, S.; Morin, D.; Dedieu, G.; Sepulcre, G.; Bontemps, S.; Defourny, P.; Koetz, B. Assessment of an operational system for crop type map production using high temporal and spatial resolution satellite optical imagery. Remote Sens. 2015, 7, 12356-12379. [CrossRef]

16. Belgiu, M.; Csillik, O. Sentinel-2 cropland mapping using pixel-based and object-based time-weighted dynamic time warping analysis. Remote Sens. Environ. 2018, 204, 509-523. [CrossRef]

17. Johansen, K.; Sallam, N.; Robson, A.; Samson, P.; Chandler, K.; Derby, L.; Eaton, A.; Jennings, J. Using GeoEye-1 Imagery for Multi-Temporal Object-Based Detection of Canegrub Damage in Sugarcane Fields in Queensland, Australia. GIScience Remote Sens. 2018, 55, 285-305. [CrossRef]

18. Ćulibrk, D.; Lugonja, P.; Minić, V.; Crnojević, V. Water-stressed crops detection using multispectral worldview-2 satellite imagery. Int. J. Artif. Intell. 2012, 9, 123-139. [CrossRef]

19. Zhao, J.L.; Zhang, D.Y.; Luo, J.H.; Huang, S.L.; Dong, Y.Y.; Huang, W.J. Detection and mapping of hail damage to corn using domestic remotely sensed data in China. Austral. J. Crop Sci. 2012, 6, 101-108. 
20. Anderson, K.; Gaston, K.J. Lightweight unmanned aerial vehicles will revolutionize spatial ecology. Front. Ecol. Environ. 2013, 11, 138-146. [CrossRef]

21. Zhang, J.; Hu, J.; Lian, J.; Fan, Z.; Ouyang, X.; Ye, W. Seeing the forest from drones: Testing the potential of lightweight drones as a tool for long-term forest monitoring. Biol. Conserv. 2016, 198, 60-69. [CrossRef]

22. Ribeiro-Gomes, K.; Hernandez-Lopez, D.; Ballesteros, R.; Moreno, M.A. Approximate georeferencing and automatic blurred image detection to reduce the costs of UAV use in environmental and agricultural applications. Biosyst. Eng. 2016, 151, 308-327. [CrossRef]

23. Huang, Y.; Reddy, K.N.; Fletcher, R.S.; Pennington, D. UAV Low-Altitude Remote Sensing for Precision Weed Management. Weed Technol. 2018, 32, 2-6. [CrossRef]

24. Zhang, C.; Kovacs, J.M. The application of small unmanned aerial systems for precision agriculture: A review. Precis. Agric. 2012, 13, 693-712. [CrossRef]

25. Stanton, C.; Starek, M.J.; Elliott, N.; Brewer, M.; Maeda, M.M.; Chu, T. Unmanned aircraft system-derived crop height and normalized difference vegetation index metrics for sorghum yield and aphid stress assessment. J. Appl. Remote Sens. 2017, 11, 026035. [CrossRef]

26. Su, B.F.; Xue, J.R.; Xie, C.Y.; Fang, Y.L.; Song, Y.Y.; Fuentes, S. Digital surface model applied to unmanned aerial vehicle based photogrammetry to assess potential biotic or abiotic effects on grapevine canopies. Int. J. Agric. Biol. Eng. 2016, 9, 119-130. [CrossRef]

27. Zhou, J.; Pavek, M.J.; Shelton, S.C.; Holden, Z.J.; Sankaran, S. Aerial multispectral imaging for crop hail damage assessment in potato. Comput. Electron. Agric. 2016, 127, 406-412. [CrossRef]

28. Su, J.; Liu, C.; Coombes, M.; Hu, X.; Wang, C.; Xu, X.; Li, Q.; Guo, L.; Chen, W. Wheat yellow rust monitoring by learning from multispectral UAV aerial imagery. Comput. Electron. Agric. 2018, 155, 157-166. [CrossRef]

29. Fernández-Guisuraga, J.M.; Sanz-Ablanedo, E.; Suárez-Seoane, S.; Calvo, L. Using unmanned aerial vehicles in postfire vegetation survey campaigns through large and heterogeneous areas: Opportunities and challenges. Sensors 2018, 18, 586. [CrossRef]

30. Fraser, R.H.; Van Der Sluijs, J.; Hall, R.J. Calibrating Satellite-Based Indices of Burn Severity from UAV-Derived Metrics of a Burned Boreal Forest in NWT, Canada. Remote Sens. 2017, 9, 279. [CrossRef]

31. Pla, M.; Duane, A.; Brotons, L. Potencial de las imágenes UAV como datos de verdad terreno para la clasificación de la severidad de quema de imágenes landsat: Aproximaciones a un producto útil para la gestión post incendio. Rev. Teledetec. 2017, 2017, 91-102. [CrossRef]

32. Bertolero, A.; Rivaes, S.; Mougeot, F.; Sánchez-Barbudo, I.S.; Andree, K.B.; Ibáñez, C. Sexing and Ageing the Purple Swamphen Porphyrio porphyrio porphyrio by Plumage and Biometry. Ardeola 2016, 63, 261-277. [CrossRef]

33. BOE. Ley 42/2007, de 13 de diciembre, del Patrimonio Natural y de la Biodiversidad; BOE: Madrid, Spain, 2007.

34. Vuolo, F.; Żółtak, M.; Pipitone, C.; Zappa, L.; Wenng, H.; Immitzer, M.; Weiss, M.; Baret, F.; Atzberger, C. Data Service Platform for Sentinel-2 Surface Reflectance and Value-Added Products: System Use and Examples. Remote Sens. 2016, 8, 938. [CrossRef]

35. Banu, T.P.; Borlea, G.F.; Banu, C. The Use of Drones in Forestry. J. Environ. Sci. Eng. B 2016. [CrossRef]

36. Iqbal, F.; Lucieer, A.; Barry, K. Simplified radiometric calibration for UAS- mounted multispectral sensor. Eur. J. Remote Sens. 2018, 51, 301-313. [CrossRef]

37. Puliti, S.; Olerka, H.; Gobakken, T.; Næsset, E. Inventory of Small Forest Areas Using an Unmanned Aerial System. Remote Sens. 2015, 7, 9632-9654. [CrossRef]

38. Näsi, R.; Honkavaara, E.; Lyytikäinen-Saarenmaa, P.; Blomqvist, M.; Litkey, P.; Hakala, T.; Viljanen, N.; Kantola, T.; Tanhuanpää, T.; Holopainen, M. Using UAV-based photogrammetry and hyperspectral imaging for mapping bark beetle damage at tree-level. Remote Sens. 2015, 7, 15467-15493. [CrossRef]

39. Ruzgiene, B.; Berteška, T.; Gečyte, S.; Jakubauskiene, E.; Aksamitauskas, V.Č. The surface modelling based on UAV Photogrammetry and qualitative estimation. Measurement 2015, 73, 619-627. [CrossRef]

40. Zahawi, R.A.; Dandois, J.P.; Holl, K.D.; Nadwodny, D.; Reid, J.L.; Ellis, E.C. Using lightweight unmanned aerial vehicles to monitor tropical forest recovery. Biol. Conserv. 2015, 186, 287-295. [CrossRef]

41. Rouse, J.W.; Hass, R.H.; Schell, J.A.; Deering, D.W. Monitoring vegetation systems in the great plains with ERTS. Third Earth Resour. Technol. Satell. Symp. 1973, 1, 309-317. 
42. Zhang, T.; Chen, W. Potential Bands of Sentinel-2A Satellite for Classification Problems in Precision Agriculture. Int. J. Autom. Comput. 2019. [CrossRef]

43. Piñeiro, G.; Perelman, S.; Guerschman, J.P.; Paruelo, J.M. How to evaluate models: Observed vs. predicted or predicted vs. observed? Ecol. Modell. 2008, 216, 316-322. [CrossRef]

(C) 2019 by the authors. Licensee MDPI, Basel, Switzerland. This article is an open access article distributed under the terms and conditions of the Creative Commons Attribution (CC BY) license (http://creativecommons.org/licenses/by/4.0/). 